\title{
Relações entre a Agroecologia e o Sensoriamento Remoto: A Centralidade da Imagem como um Processo de Construção da Realidade
}

\section{Francisco Martellini*, Roberto Donato da Silva Júnior}

\section{Resumo}

Pretende-se aqui analisar como artigos sobre agroecologia estão usando conceitualmente as imagens geradas pelo sensoriamento remoto, refletindo se e como validam o conhecimento científico através dos estudos sociais das ciências, mostrando que mesmo com o pluralismo de valores da agroecologia, os modelos convencionais de validação científica ainda se mantém, ignorando a subjetividade inerente aos envolvidos na geração e no uso das imagens.

\section{Palavras-chave:}

Agroecologia, Sensoriamento Remoto, Estudos Sociais das Ciências.

\section{Introdução}

O projeto foi fundamentado nas possibilidades interdisciplinares entre as técnicas de sensoriamento remoto e a agroecologia, buscando entender suas motivações e de que formas elas acontecem. A agroecologia, segundo Aquino (2005, p. 97) possui um pluralismo na produção do conhecimento que contribui para superar a ideia de supremacia das ciências naturais. Já o sensoriamento remoto, um conjunto de técnicas para obtenção de imagens da superfície terrestre, apresenta implicações sociais e ambientais que vão além do fator tecnológico.

$\mathrm{Na}$ interação destes contextos, as questões ambientais, são confrontadas com seus próprios produtos, carências e tribulações, estendendo a dúvida científica aos efeitos externos da própria ciência (BECK, 2011, p. 235). Busca-se com isso refletir sobre a imagem como forma de validação do conhecimento científico, compreendendo, segundo Monteiro $(2015$, p. 578$)$ sua centralidade, e pensando para além de suas representações visuais.

\section{Resultados e Discussão}

Selecionou-se cinco artigos das bases Web of Science, Scielo e Google Acadêmico, mostrados no Quadro 1.

\section{Quadro 1. Artigos selecionados para análise.}

BARBOSA, Íris do S.; ANDRADE, Leonaldo A. de; ALMEIDA, José A. P. de. Zoneamento agroecológico do município de Lagoa Seca, PB. Rev. bras. eng. agríc. ambient., Campina Grande, v. 13, n. 5, p. 623-632, out. 2009 .

VIEIRA, Marcos Meneses et al. Delimitação das áreas de preservação permanente do terço superior de topo de morro, para as microrregiões sudoeste serrana, litoral norte e extremo norte do estado do Espírito Santo. Revista Brasileira de Agroecologia, [S.I.], v. 6, n. 2, p. 142-151, 2011.

BOLFE, Édson Luis; BATISTELLA, Mateus. Análise florística e estrutural de sistemas silviagrícolas em Tomé-Açu, Pará. Pesq. agropec. bras., Brasília, v. 46, n. 10, p. 1139-1147, out. 2011.

BOLFE, Édson Luis; BATISTELLA, Mateus; FERREIRA, Marcos César. Correlação de variáveis espectrais e estoque de carbono da biomassa aérea de sistemas agroflorestais. Pesq. agropec. bras., Brasília , v. 47, n. 9, p. 1261-1269, set. 2012.

BLINN, Christine E. et al. Rebuilding the Brazilian rainforest: Agroforestry strategies for secondary forest succession. Applied Geography, v. 43, p. 171-181, 2013.

Fonte: elaboração própria
O estudo foi fundamentado na sociologia do conhecimento científico, cuja hipótese central diz que há fatores de natureza social, condicionantes ou mesmo determinantes não apenas na produção de conhecimento no sentido amplo, mas, mesmo na lógica da descoberta científica (RODRIGUES, 2005, p. 116). Com base nisso, os principais critérios para a análise dos documentos são (i) o uso no sentido técnico das imagens, (ii) os critérios para sua construção, (iii) que proposituras resultam delas.

\section{Conclusões}

Partindo do princípio que o conhecimento científico envolvido na pesquisa foi submetido a mesma análise interdisciplinar utilizada pelas ciências sociais, foi possível entender a relação entre um objeto técnico e a questão ambiental, enfatizando que o método científico e a tecnologia não podem ser entendidos isoladamente das práticas humanas com as quais estão envolvidos.

De forma mais específica, mesmo com o pluralismo de valores da agroecologia, os artigos estudados mostram que os modelos convencionais de validação científica ainda se mantém, ignorando a subjetividade inerente aos envolvidos na geração e no uso das imagens de satélite.

\section{Agradecimentos}

Agradeço a meu orientador Roberto Donato da Silva Júnior, ao grupo de estudos "Ciências, Ambientes e Interdisciplinaridades" (CAI) da FCA/Unicamp, ao corpo docente desta instituição, e ao Conselho Nacional de Desenvolvimento Científico e Tecnológico (CNPq). Sem eles, este projeto não existiria.

AQUINO, Adriana Maria de; ASSIS, Renato Linhares de (orgs.). Agroecologia: princípios e técnicas para uma agricultura orgânica sustentável. Brasília, DF: Embrapa, 2005, 517 p.

BECK, Ulrich. Sociedade de risco: rumo a uma outra modernidade. $2^{\text {a }}$ ed. São Paulo: Editora 34, 2011. 384 p.

MONTEIRO, Marko. Construindo imagens e territórios: pensando a visualidade e a materialidade do sensoriamento remoto. Hist. cienc. saúde-Manguinhos, Rio de Janeiro , v. 22, n. 2, p. 577-591, Apr. 2015. RODRIGUES, Léo Peixoto. Introdução à sociologia do conhecimento, da ciência e do conhecimento científico. Passo Fundo, RS: Editora da UPF, 2005. 143 p. 